\title{
Dispensing errors and uncertainty: Perspectives of pharmacists in a tertiary health facility in Lagos, Nigeria
}

\author{
Emmanuel N. Anyika*, Omolara Y. Omosebi \\ Department of Clinical Pharmacy \& Biopharmacy, Faculty of Pharmacy, University of Lagos, Lagos, Nigeria
}

Received: September 29, 2015

DOI: $10.5430 /$ jha.v5n1p100
Accepted: November 4, $2015 \quad$ Online Published: December 8, 2015

URL: http://dx.doi.org/10.5430/jha.v5n1p100

\begin{abstract}
Introduction: Dispensing errors (DE) and health care uncertainty impact on health outcomes in a variety of ways. The aim of initiating therapy is to enhance patient wellness but human error probabilities sometimes cause harm or even fatalities and litigations.

Objective: The aims of this study are to discuss the underlying factors in dispensing errors, health care uncertainty and therapeutic outcomes, and to identify the extent of human- and system-based sources of errors by exploring hospital pharmacists' attitudes and dispositions to DE and uncertainties; and the implications for patient safety in a tertiary hospital.

Methods: The study involved a sample of 44 pharmacists who were administered a survey research inventory designed to assess pharmacists' attitudes and involvement in DE and uncertainty on a variety of important dimensions.

Results: Overall the survey research data showed high rating of five human-based dimensions that would minimize dispensing errors, two human-system based, while three system-based (structural) issues were rated as dimensions that would aggravate DE in uncertain health care scenarios.

Conclusions: The practical importance of the results for pharmacy practice and therapeutic outcomes are discussed and some suggestions made on how to minimize DE and uncertainty and the policy implications in the hospital pharmacy setting.
\end{abstract}

Key Words: Dispensing errors, Uncertainty, Hospital pharmacists, Perspectives, Health outcome

\section{INTRODUCTION}

Dispensing errors (DE) are common occurrence in hospital settings around the globe. Some of the errors if undetected by pharmacists, could cause serious or life-threatening adverse drug events. ${ }^{[1]}$ Categories of DE include failure to: detect and correct prescribing or manufacturing errors before dispensing. ${ }^{[2]}$ Preventive strategies to reduce the incidence of DE target all stages of drug delivery process. ${ }^{[3]}$ There is always an elicited probability distribution describing uncer- tainty about the proportion of occasions in which a pharmacist will detect wrong dose prescription error. ${ }^{[4]}$ Sources of uncertainty in health care include probability, ambiguity and complexity. ${ }^{[5]}$

\subsection{Statement of problem}

$\mathrm{DE}$ and the attendant health care uncertainties continue to pose challenges to therapeutic outcomes, more so with increasing number of patients, new and sophisticated medi-

\footnotetext{
*Correspondence: Emmanuel N. Anyika; Email: emmaboogie22@yahoo.com; Address: Department of Clinical Pharmacy \& Biopharmacy, Faculty of Pharmacy, University of Lagos, Lagos, Nigeria.
} 
cations, workload, environmental disturbances, lack of adequate manpower and relevant enabling technologies, and limited awareness of the enormity of DE in our uncertain health care delivery environment. Harm to patients, fatalities and litigations have been reported. ${ }^{[6]}$ The pharmacists' role in minimizing DE and uncertainty in our hospital environment has not been widely investigated. ${ }^{[7]}$

\subsection{Objectives of the study}

The objectives of the study are: to discuss the underlying factors in dispensing errors, uncertainty and health outcomes, and to identify human- and system-based sources of errors prevalent in the tertiary institution and their implications for patient safety (see Figure 1).

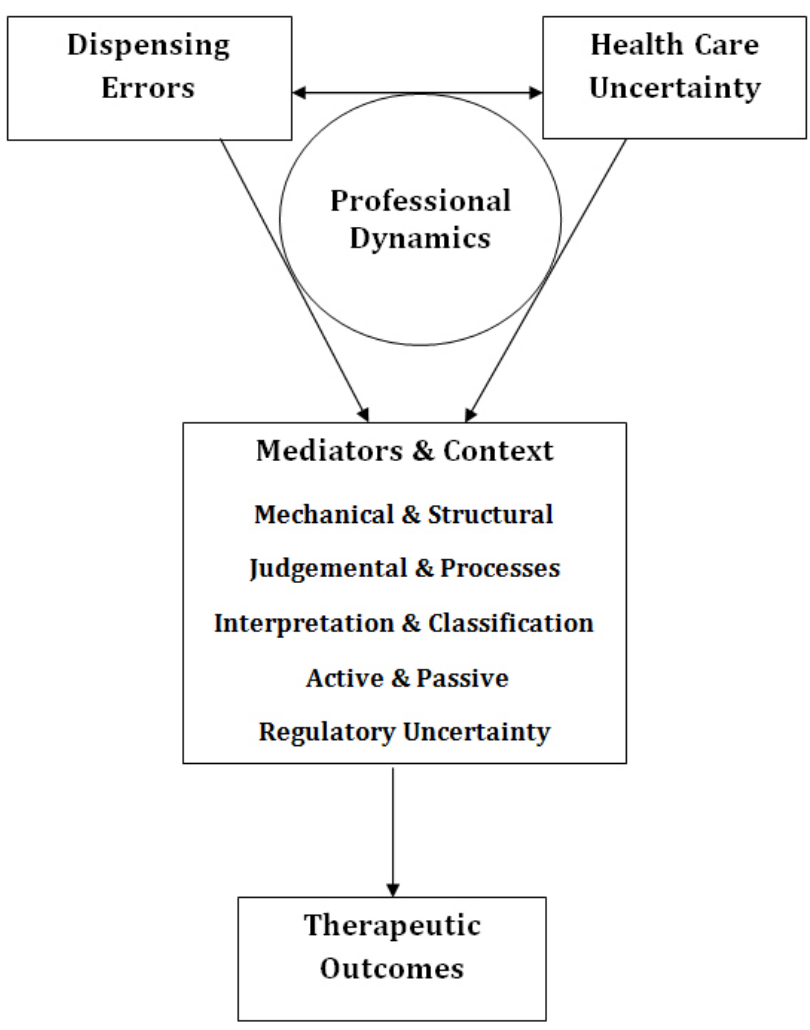

Figure 1. Relationship between dispensing errors, health care uncertainty and therapeutic outcomes

\subsubsection{Dispensing errors}

The problems and sources of medication error are multidisciplinary and multi-factorial, with a variety of complex contributing factors combining to cause indicents. ${ }^{[8]} \mathrm{DE}$ in addition to causing serious morbidity and mortality, also increase the economic burden on the society by adding to care costs and litigation. ${ }^{[9]}$ Reason $^{[10]}$ viewed errors from the active and latent perspectives. Latent errors are less apparent failures of organization or design that contributed to the occurrence of errors or allowed them to cause harm to patients, while active failure or errors occur at the point of contact between a human and some aspects of a larger system. The influx of new drugs with names that look-alike and sound-alike has made prescription interpretation more difficult, thereby aggravating dispensing errors. ${ }^{[11]}$ Error in dispensing can be traumatic for the patient and pharmacist. It compromises the patient's confidence in the health care system and creates uncertainty for repeat patronage. High prescription volumes, pharmacist fatigue and overwork are possible important factors, requiring proactive and elevated zero error standard of practice to minimize uncertainty. ${ }^{[12,13]}$

DE at work tend to increase with high level of interruption, distraction, noise, exhaustion, illegible doctor's prescription, failure to check patient's name with prescription, wrong dose calculation, absent-mindedness, incorrect drug, poor labels, wrong time of dispensing, talkative patients or clients and patients in a hurry. ${ }^{[2,13-17]}$ Pharmacist's error could be mechanical or judgmental. ${ }^{[18]}$ Other DE could be errors of omission or commission. ${ }^{[19]}$ Effective risk management of DE requires a reporting culture. Medication errors are a leading cause of mortality in the US. ${ }^{[20]}$ Despite improved technology in health care setting, errors and harm related to medication use still occurred in about $18 \%$ of patient admissions.

\subsubsection{Professional dynamics}

The professional roles, attitude and disposition towards pharmaceutical health care and DE are all aspects of professional dynamics. The individual and collective responsibilities of pharmacists to patient care, the effective use of technology and manpower development constitute professional dynamics in this context. The interpretation and classification of events in hospitals was influenced by professional responsibility, event contingencies and surveillance technology. ${ }^{[21,22]}$ Pharmacists have the capacity to enhance therapeutic outcomes and patient's quality of life through patient-care activities and management of drug supplies. Leape et al. ${ }^{[23]}$ used pathway for medicines in hospitals as a way of standardizing care mapping processes and possibly identifying generic medication hazard points (opportunities for error). Studies on dispensing error rates show that the dispensing process is relatively safe, with multiple studies reporting a narrow range of dispensing error rates; but proactive detection of errors is likely to underestimate the true error rate - giving rise in error rate of magnitude $350-920$ per 100,000 compared to 18 per 100,000 orders. ${ }^{[24,25]}$

Having additional pharmacists in the wards has greater potential for net benefits than bar coding systems. ${ }^{[4]}$ Hospital pharmacists in developing countries do not have viable systems of preventing and detecting drug or dose detection errors when filling prescriptions containing high alert medications 
due to lack of technologies. Human error probabilities are classified based on the extent of probability of error: high, moderate, low and lowest limits of human error. ${ }^{[26]}$ There is a probability distribution of uncertainty about a pharmacist's detection of wrong dose prescription error. ${ }^{[4]}$

\subsubsection{Health care uncertainty and dispensing errors}

Uncertainty is a fact of life for every practicing health care professional and it is regarded as central in the diagnosis of illness and in the process of alleviating it. ${ }^{[27]}$ There are multiple meanings and varieties of uncertainty in health care. Uncertainty associated with dispensing error falls into three categories, according to its fundamental sources, issues and locus, ${ }^{[5]}$ and include: a probability (clinical uncertainty), ambiguity (imprecision of estimates), and complexity (multifactorial and multi-disciplinary). ${ }^{[5,28]}$ It could also result from living within complex adaptive systems where varying mixes of natural and man-made (mechanical/structural) systems interact and resist control. ${ }^{[29]}$ In health care, judgment and decision tasks are uncertain - characterized by uncertainty of information or outcome or by a concern for a person's preferences. ${ }^{[30]}$ Task and team factors involving teaching and training of health professionals, schedules and assignments, communication and collaboration, are issues that affect DE with varying degrees of uncertainty. Uncertain environmental factors in hospital leadership, the hospital policy, the extent of use and depth of hospital drug formulary will affect uncertainty and dispensing errors. ${ }^{[5,31]}$

\subsubsection{Mediators and contextual issues}

A number of contextual and multi-factorial issues combine with core values and professional expectations in a practice environment to mediate the impact of DE on the therapeutic outcomes. They could be in the form of: human- and system-based, mechanical and structural, judgmental and processes, interpretation and classification of errors/uncertainty, active and latent mediators, and issues of regulatory uncertainty and potential litigations arising from dispensing errors. The practical issues of uncertainty in health care include the structures and processes, which are system based. ${ }^{[5]}$ Power outages, and dilapidated infrastructure in some public health institutions in Nigeria, do affect the storage conditions of medicines and vaccines, and could generate dispensing errors and uncertainty in the quality of drugs that get to the patient. ${ }^{[28,32]}$

\subsubsection{Uncertainty and therapeutic outcomes}

One of the domains of uncertainty in health care is treatment, which involves risks and benefits of therapeutic interventions. ${ }^{[5]}$ Sommers and Launer ${ }^{[29]}$ posit that when uncertainty is high in a health setting, quality emerges through adaptive relationships, collective sense-making and on-the-job learn- ing from one another. The impact of uncertainty in various aspects of health care delivery system has been documented, especially in the areas of decision making, operations, interprofessional collaboration, coping behavior of patients, and doctors, and in nursing practice setting. ${ }^{[27,33-35]}$

This work therefore aims to identify the forms of dispensing errors, and uncertainty in the tertiary hospital and their implications for patient safety.

\section{Methods}

The sample comprised 50 fully registered pharmacists (who have completed the post-graduation one year each, of internship and national service) in a tertiary health facility in Lagos. A 10-item attitude/involvement inventory was constructed and pilot-tested for the purpose of data collection on pharmacists' perspectives on different dimensions of DE and uncertainty.

The Likert-type rating scale comprises 10 items, on a fourpoint continuum. Pharmacists were asked to self-assess and rate $\mathrm{DE}$ and uncertainty in the tertiary hospital on the following 10 different dimensions (e.g. [a] Ever committed DE in the past one year? 1 = Usually, 4 = Hardly; [b] Ever reported DE when it happened? 1 = Hardly, $4=$ Usually, etc.) (see Table 1). Individual scales were combined linearly and averaged, using equal weights to form a composite attitude/involvement scale, with higher scores indicating less involvement in dispensing errors. The stimuli are arranged in a counter-balanced order of lowest to highest (1-4 in the brackets) on the inventory, based on the perceived involvement in reducing DE and uncertainty.

\section{RESULTS}

Out of 50 questionnaires that were self-administered to the respondents in a voluntary situation, only 44 were completed and suitable for data collection and analysis. Of this number, eight $(18.2 \%)$ of the respondents were males, while 36 $(81.8 \%)$ were females.

Table 1 shows the attitude and involvement scale ratings of DE and uncertainty. Table 2 shows the attitude and involvement scale ratings of $\mathrm{DE}$ and uncertainty with the means and standard deviations $(S D)$. High error ratings were observed in seven dimensions of: committing dispensing errors, reporting, clarification of prescriptions, supervising staff, inter-professional relations, availability of information and structural/environmental effects. Use of technologies, high work pressure and staff inadequacy for the existing workload were rated low, all of which have implications for aggravating prescribing errors. 
Table 1. Attitude and involvement scale ratings of DE \& uncertainty

\begin{tabular}{|c|c|c|c|c|}
\hline \multirow{2}{*}{ Scale } & \multicolumn{4}{|c|}{ DE \& uncertainty (Score) } \\
\hline & Usually & Sometimes & Rarely & Hardly \\
\hline Ever committed DE in past one year? & $0(1)$ & $5(2)$ & $36(3)$ & $3(4)$ \\
\hline Ever reported DE when it happened? & $17(4)$ & $8(3)$ & $14(2)$ & $5(1)$ \\
\hline Ever clarified difficult prescriptions with colleagues? & $19(4)$ & $15(3)$ & $0(2)$ & $0(1)$ \\
\hline Ever supervised interns/technicians on DE? & $29(4)$ & $11(3)$ & $4(2)$ & $0(1)$ \\
\hline Ever used technologies (e.g. bar coding) to reduce DE \& uncertainty? & $0(4)$ & $0(3)$ & $0(2)$ & $44(1)$ \\
\hline Does higher work pressure increase chance of DE \& uncertainty? & $25(1)$ & $19(2)$ & $0(3)$ & $0(4)$ \\
\hline Is staff strength adequate for work load in pharmacy? & $0(4)$ & $0(3)$ & $35(2)$ & $9(1)$ \\
\hline Do doctors \& pharmacists work as team to reduce DE \& uncertainty? & $2(4)$ & $12(3)$ & $22(2)$ & $8(1)$ \\
\hline Is information available for $\mathrm{DE}$ decision making? & $6(4)$ & $21(3)$ & $14(2)$ & $3(1)$ \\
\hline Do current structural outlay and environmental conditions increase DE \& uncertainty? & $3(1)$ & $23(2)$ & $13(3)$ & $5(4)$ \\
\hline
\end{tabular}

Note. DE: Dispensing errors

Table 2. Attitude and involvement scale ratings of DE \& uncertainty: means and $S D$

\begin{tabular}{lll}
\hline Scale & Mean & SD \\
\hline Committed DE & 2.97 & 1.15 \\
Reported DE & 2.85 & 0.60 \\
Clarified difficult prescriptions & 2.75 & 0.85 \\
Supervised staff on DE & 3.57 & 1.21 \\
Used technologies to reduce DE & 1.00 & 0.50 \\
Higher work pressure increase DE & 1.43 & 0.43 \\
Staff adequacy for pharmacy workload & 1.79 & 0.77 \\
Inter-professional teamwork on DE & 2.18 & 0.43 \\
Available information for DE reduction & 2.69 & 0.69 \\
Structural outlay/environment on DE & 2.46 & 0.44 \\
\hline
\end{tabular}

Note. DE: Dispensing errors

These findings implicate the poor use of technologies, high work pressure, and staff inadequacy as the highest risk factors for DE and uncertainty, while a good number of dimensions have palpable degrees of risk factors.

The range and $S D$ at $95 \%$ confidence interval are: $2.37 \pm 1.36$. The range of the mean scores is from 1.01 to $3.73(p=.05)$.

\section{Discussion AND CONCLUSION}

The use of attitude and involvement scale ratings on different dimensions of DE and uncertainty gives a lucid presentation of the frequency and magnitude of occurrence of humanand system-based errors in the hospital. The scale rating gives numerical values to various aspects of dispensing errors, thereby providing information on the areas that need improvement. The data presented are consistent with the various streams of evidence in literature showing that $\mathrm{DE}$ do occur significantly for most of the dimensions investigated. Respondents admitted committing DE (Scale: 2.97), which are also common occurrence in hospital settings ${ }^{[1,3]}$ How- ever the risks and hazards associated with these errors should be reduced by targeting their root causes. Moderately high error reporting was recorded by respondents. Error reporting should be encouraged in hospital settings by using the system approach that copes with avoidable medical errors through team work and other strategies for managing uncertainty, instead of the individual approach to human fallibility, which involves blame games and defenses. ${ }^{[36]}$

Respondents also clarified difficult prescriptions with their senior colleagues to a reasonable extent (Scale: 2.75) before dispensing. It is in line with managing potentially harmful events before they occur in a proactive sense, which is a critical factor in risk management. ${ }^{[37]}$ The supervision of internees and pharmacy technicians was carried out to a very high degree, which is also crucial in the reduction of DE in hospital settings, as shown in the degree of involvement of respondents (Scale: 3.57). This corroborates with the works of Edmondson, ${ }^{[37]}$ and Lubinga et al. ${ }^{[38]}$ that emphasized the importance of leadership in encouraging team learning to maximize patient safety. Respondents reported minimal use of technologies (Scale: 1.0), which serve as enabling tools in facilitating dispensing activities and minimizing errors. Researchers have shown that electronic health records (EHR), computerized prescription order entry (CPOE) technologies and e-pharmacy are very beneficial in error and cost minimization, dispensing high-alert medications, and improved patient outcomes ${ }^{[39-42]}$ while some reports show mixed benefits. ${ }^{[26,43]}$ These technologies if made available in our practice setting would minimize errors and uncertainty, and enhance quality of care to the patients.

Respondents perceived high work pressure to exacerbate dispensing error - with a scale rating of 1.43 . The result was also corroborated by the work of Teinila et al. ${ }^{[13]}$ prompting the need to recommend the employment of more pharma- 
cists or the utilization of manpower scheduling strategies, with discrete-event stimulation, particularly in the out-patient pharmacy. ${ }^{[44]}$ The same also applies to staff inadequacy for the workload (Scale: 1.79) in the in-patient, out-patient, and other satellite pharmacies. Further decentralization, adequate manpower deployment and staff training on DE will minimize dispensing mistakes and uncertainty. ${ }^{[14]}$ Interprofessional teamwork was rated average (Scale: 2.18). However, in real work situation, hospital pharmacists in Nigeria are yet to be integrated as vital members of health care delivery at ward level, since the clinical pharmacy practice is still rudimentary in Nigeria hospitals. ${ }^{[4]}$ The challenge resulting from team factors and poor communication among health professionals has aggravated medication (prescribing and dispensing) errors due to lack of team work and synergy. Effort should be made to minimize errors through joint training of health team members on medication errors and uncertainty.

Reference books which are information sources should be made available to pharmacists and prescribers to aid in making informed decisions and mitigate the occurrence of medication errors. Although available information for DE reduction was rated moderately high (Scale: 2.69), the ready availability of reference books, formulary systems and technologies will be very useful in error minimization ${ }^{[26,31]}$ in dispensing environments. Respondents perceived the structural outlay and physical environment as risk factors for DE (Scale: 2.46). This is also supported by the findings of Reason, ${ }^{[10]}$ which subscribe among others that an enabling environment with minimal stressors will reduce dispensing mistakes and enhance patient safety. Direct pharmacist feedback on these errors is therefore an important consideration in minimizing dispensing errors, adverse drug events and uncertainty. These research findings are potentially valuable source of information, which could be used to tackle institution-specific proneness to dispensing errors.

With the multiplicity of risk factors in our environment, there is urgent need to reinforce the training of pharmacists, phar-

\section{REFERENCES}

[1] Cina JL, Gandhi TK, Churchill W, et al. How many hospital pharmacy medication dispensing errors go undetected? Journal on Quality and Patient Safety. 2006; 32(2): 73-80. Available from: www.ncbi.nlm.nih.gov/pubmed/16568920

[2] Cheung KC, Bouvy ML, De Smet PA. Medication errors: the importance of safe dispensing. British Journal of Clinical Pharmacology. 2009; 67(6): 676-680. PMid: 19594537. http://dx.doi.org/10. 1111/j.1365-2125.2009.03428.x

[3] Bohand X, Simon L, Perrier E, et al. Frequency, types, and potential macy technicians, physicians and nurses; and the provision of resource materials and enabling work environment aimed at minimizing medication errors. Pharmacists should play a more dynamic role in championing the minimization these errors (drug-related problems) through higher commitment and alertness, self-updating and organizing training sessions, for the therapeutic benefit to the patients. Inter-professional teamwork should be encouraged to minimize errors arising from slips in prescription writing, which could be dispensed unnoticed. Health leaders and administrators should provide adequate and modern infrastructure in the pharmacies, for the development of a health system that aims to achieve zero-tolerance to medication errors, for enhanced patient safety.

\subsection{Strengths of the study}

The use of attitude and involvement scale ratings on different dimensions of errors and uncertainty gives a lucid presentation of the frequency and magnitude of occurrence of humanand system-based errors in the tertiary hospital. The scale rating gives numerical values to various aspects of dispensing errors. The research findings will help to emphasize areas where DE are more likely to occur, and help pharmacy administrators and trainers to identify and minimize these generic medication hazard points (opportunities for error).

\subsection{Limitations}

From the methodological point of view, the study made use of pharmacists in only one tertiary hospital for data generation. It is possible that different results could be obtained from other health institutions if more robust sampling was carried out. Further research is required to extend the validity of the work and its generalizability. Only the dimensions of DE listed were assessed, which might have excluded other important dimensions of DE and uncertainty prevalent in the institution.

\section{Conflicts of InTEREST Disclosure}

The authors declare that they have no competing interest. clinical significance of medication-dispensing errors. Clinics (Sao Paulo). 2009; 64(1): 11-16. http://dx.doi.org/10.1590/S18 07-59322009000100003

[4] Karnon J, McIntosh A, Bath P, et al. A prospective hazard and improvement analysis of medication errors in the UK. Available from: http://www.birmingham.ac.uk/Documents...final ReportKarnon.pdf

[5] Han PKJ, Klein WMP, Arora NK. Varieties of uncertainties in health care. A conceptual taxonomy. medical decision making. 2011; 31(6): 828-838. Available from: http://www.ncbi.nlm.nih.gov/pmc 


\section{/articles/PMC3146626/}

[6] Ming KLY. A duty to care: pharmacists' negligence: implications for pharmacists and lessons arising. Allied Health Professions. 2003; 5: 1-9. Available from: https://business.cutin.edu.au/lo cal/docs/2.Vol_5_Article_2_Kelvin_Lau.pdf

[7] Iyayi OO, Igbinomwanhia RO, Iyayi F. Classification of mistakes in patient care in a Nigerian hospital. Global Journal of Medical Research Interdisciplinary. 2013; 13(3): 35-42. Available from: https://globaljournals.org/GJMR_Volume13/6-Cla ssification-of-Mistakes-in-Patients.pdf

[8] Smetzer JL, Cohen MR. Preventing medication errors. Quality Chasm Series. Hospital Pharmacy. 1998; 1-7. Available from: http: //www.nap.edu/openbook

[9] Merrills J, Fisher J. Pharmacy Law and Practice. Academic Press, Elsevier, London, $5^{\text {th }}$ ed., 2013. PMid: 24094262. Available from: http://books. google.co.uk/books?id=4a6...

[10] Reason J. Human error: models and management. British Medical Journal. 2000; 320: 768-770. PMid: 10720363. http://dx.doi.o $\mathrm{rg} / 10.1136 / \mathrm{bmj} \cdot 320.7237 .768$

[11] Smetzer J, Baker C, Byrne FD, et al. Root cause analysis. Shaping systems for better behavioral choices: lessons learned from a fatal medication error. Joint Commission Journal on Quality and Patient Safety. 2010; 1-14. Available from: psnet.ahrq.gov/public/Sm etzer-JCJQPS-2010-s4.pdf

[12] Peterson GM, Wu MSH, Bergin JK. Pharmacists' attitudes towards dispensing errors: their causes and prevention. Journal of Clinical Pharmacy and Therapeutics. 1999; 24: 57-71. PMid: 10319909. http://dx.doi.org/10.1046/j.1365-2710.1999.00199.x

[13] Teinila T, Gronroos V, Airaksinen M. A system approach to dispensing errors: A national study of perceptions of the Finnish community pharmacists. Pharmacy World and Sciences. 2008; 30: 823-833. PMid: 18574708. http://dx.doi.org/10.1007/s11096-008 -9233-4

[14] Anacleto TA, Perini E, Rosa MB, et al. Drug-dispensing errors in the hospital pharmacy. Clinics (Sao Paulo). 2007; 62(3): 243-250. http://dx.doi.org/10.1590/S1807-59322007000300007

[15] Rolland P. Occurrence of dispensing errors and efforts to reduce medication errors at the Central Arkansas Veteran's Health System. Drug Safety. 2007; 27(4): 271-282. http://dx.doi.org/10.21 65/00002018-200427040-00004

[16] Klein EG, Santora JA, Pascale PM, et al. Medication cart-filling time accuracy, and cost with an automated dispensing system. American Journal of Hospital Pharmacy. 1994; 51(9): 1193-1196. PMid: 8042638. Available from: http://www.ncbi.nlm.nih.gov/

[17] Ojerinde AC, Adejumo PO. Factors associated with medication errors among health workers in University College Hospital, Nigeria. Journal of Nursing and Health Science. 2014; 3(3): 22-23. http://dx.doi.org/10.9790/1959-03342233

[18] Abood RR. Pharmacy Practice and the Law. $5^{\text {th }}$ ed., Sudbury, MA, Jones and Bartlett Publishers Inc; 2008

[19] Lynette JK, Barlow D, McArtney R, et al. Incidence, type and causes of dispensing errors: A review of the literature. International Journal of Pharmacy Practice. 2009; 17: 9-30. http://dx.doi.org/10. 1211/ijpp.17.1.0004

[20] Nair RP, Kappil D, Woods T. Strategies for minimizing dispensing errors. Pharmacy Times. 2010; 71: 30-31. Available from: http://www.pharmacytimes/publications/issue/2 010/January2010/P2Dispensingerrors-0110

[21] Tamuz M, Thomas EJ. Classifying and interpreting threats to patient safety in hospitals: insights from aviation. Journal of Organizational behavior. 2006; 27: 919-940. http://onlinelibrary.wiley.co

Published by Sciedu Press
[22] Wholey D, Moscovice I, Hietpas T, et al. The environmental context of patient safety and medical errors. Journal of Rural Health. 2004; 20: 304-313. PMid: 15551847. http://dx.doi.org/10.1111/j $.1748-0361.2004 . t b 00044 . x$

[23] Leape LL, Kabcenell A, Berwick DM, et al. Reducing adverse drug events. Breakthrough Series Guide. Institute of Healthcare Improvements, US. 1998

[24] Poon EG, Cina JL, Churchill W, et al. Medication dispensing errors and potential adverse events before and after implementing bar code technology in the pharmacy. Annals of Internal Medicine. 2006; 145(6): 426-434. PMid: 16983130. http://dx.doi.org/10.73 26/0003-4819-145-6-200609190-00006

[25] Campbell GM, Facchinetti NJ. Using process control charts to monitor dispensing and checking errors. American J. Health System Pharmacy. 1998; 55(9): 946-952. PMid: 9588253.

[26] Cohen MR, Smetzer JL, Westphal JE, et al. Risk models to improve safety of dispensing high-alert medications in community pharmacies. Journal of American Pharmacists Association. 2012; 525(52): 584-602. PMid: 23023839. http://dx.doi.org/10.1331/JAP hA. 2012.10145

[27] Alvesson HM, Lindelow M, Khanthaphat B, et al. Coping with uncertainty during healthcare-seeking in Lao PDR. BMC International Health and Human Rights. 2013; 13: 28. PMid: 23777408 http://dx.doi.org/10.1186/1472-698X-13-28

[28] Anyika EN. Challenges of implementing sustainable health care delivery in Nigeria under environmental uncertainty. Journal of Hospital Administration. 2014; 3(6): 113-126. http://dx.doi .org/10.54 $30 / j h a \cdot v 3 n 6 p 113$

[29] Sommers LS, Launer J. Clinical uncertainty in primary care: the challenge of collaborative engagement. New York: Springer Science+ Business Media. 2013; 12-15.

[30] Thompson C, Dowding D. Responding to uncertainty in nursing practice. International Journal of Nursing Studies. 2001; 38: 609-615. http://dx.doi.org/10.1016/S0020-7489(00)00103-6

[31] Leape LL. Error in Medicine. JAMA. 1994; 272(23): 1851-1857. PMid: 7503827. http://dx.doi.org/10.1001/jama.1994.0 3520230061039

[32] Obansa SA, Orimisan A. Health care financing in Nigeria: Prospects and challenges. Mediterranean Journal of Social Sciences [Internet]. 2013; 4(1): 221-236. Available from: http://www.mcser.org/images/stories/mjss.janu ary.2013/s.a.j.obansa-health-caref inancing.pdf

[33] Oishi A, Murtagh FEM. The challenges of uncertainty and interprofessional collaboration in palliative care for non-cancer patients in the community: A systematic review of views from patients, carers and healthcare professionals. SAGE Journals [Internet]. 2014 Available from: http://pmj . sagepub.com/content/early/20 14/05/09/026921631453199.../

[34] Kostopoulou O, Wildman M. Sources of variability in uncertain medical decisions in the ICU: A process tracing study. Qual. Safe Health Care [Internet]. 2004; 13(4): 272-280. Available from: http: //www.ncb.nlm.nih.gov/pmc/articles/PMC1743866/

[35] Hupert N, Xiong W, King K, et al. Uncertainty and operational considerations in mass prophylaxis workforce planning. Disaster Med Public Health Prep. 2009; 3(Suppl 2): 121-131. PMid: 19797960. http://dx.doi.org/10.1097/DMP. 0b013e3181be9c39

[36] La Pietra L, Calligaris L, Molendini L, et al. Medical errors and clinical risk management : state of the art. Act Otorhinolaryngolital 2005; 25(6): 339-346. Available from: www.ncbi.nlm.nih.gov/p mc/articles/PMC2639900/

[37] Edmundson AC. Learning from failure in the healthcare: frequent opportunities, pervasive barriers. BMJ Quality \& Safety. 2004; 13: 
i3-i9. Available from: qualitysafety. bmj.com/content/13/s uppl_2/ii3.short

[38] Lubinga SJ, Jenny AM, Larsen-Cooper E, et al. Impact of pharmacy worker, training and development on access to essential medicines and health outcomes in Malawi: protocol for a cluster quasi- experimental evaluation. Implementation Science. 2014; 9: 156. PMid: 25300317. http://dx.doi .org/10.1186/s13012-0 14-0156-2

[39] Spaulding TJ, Raghu TS. Impact of CPOE usage on medication management process costs and quality outcomes. The Journal of Health Care Organization, Provision and Financing. 2013; 5(3): 229247. Available from: inq. sageub.com/content/50/30/229.f ull.pdf+html

[40] Varshney U. Smart medication management system and multiple interventions for medication adherence. Decision Support Systems. 2013; 55(2): 538-551. http://dx.doi.org/10.1016/j.dss.2 012.10 .011

[41] Nuckols TK, Smith-Spangler C, Morton SC, et al. The effectiveness of computerized order entry at reducing preventable adverse drug events and medication errors in hospital settings: a systematic re- view and meta-analysis. Systematic Reviews. 2014; 3: 56. PMid: 24894078. http://dx.doi.org/10.1186/2046-4053-3-56

[42] Bigirimana S, Chinembiri M. Towards e-pharmacy: the future information and communication technologies needs for community pharmacies in Harare, Zimbabwe. International Journal of Economics, Commerce \& Management. 2015; 3(4). Available from: i jecm.co.uk/wp-content/uploads/2015/04/3462.pdf

[43] StromBL, Schinnar R, Aberra F, et al. Unintended effects of a computerized physician order entry nearly hard-stop alert to prevent a drug interaction: a randomized control trial. Arch Intern Med. 2010; 170(17): 1578-1583. PMid: 20876410. http://dx.doi.org/10. 1001/archinternmed.2010.324

[44] Choon OH, Leng CW, Ai WJ, et al. Evaluation of manpower scheduling strategies at outpatient pharmacy with discrete- event simulation. OR Insight. 2013; 26: 71-84. Available from: www . palgrave- jou rnals.com/ori/journal/v26/n1/full/ori20129a.html

[45] Ajemigbitse AA, Omole MK, Osi-Ogbu OF, et al. A qualitative study of causes of prescribing errors among junior medical doctors in a Nigeria in-patient setting. Annals of African Medicine. 2013; 12(4): 223- 231. PMid: 24309411. http://dx. doi .org/10.4103/159 $6-3519.122691$ 